\title{
Association among different measures of alcohol use across adolescence and emerging adulthood
}

\author{
Kara Thompson, Tim Stockwell, Bonnie Leadbeater, and Jacqueline Homel \\ Centre for Addiction Research of British Columbia, Department of Psychology, University of \\ Victoria, Victoria, BC, Canada
}

\section{Abstract}

Background and Aims-The use of alterative alcohol indices in developmental research may generate conflicting findings in the literature. This study examined the longitudinal associations among four indices of alcohol involvement from ages 15 to 25 years and examined their concurrent associations with alcohol-related problems in emerging adulthood.

Design-Data are from the Victoria Healthy Youth Survey, a five-wave multi-cohort study conducted biennially in Victoria, Canada between 2003 and 2011.

Setting and Participants-This study included a subsample of 637 randomly recruited Canadian adolescents, aged 15-25 years.

Measurements-Four indices of alcohol use were compared using multivariate piecewise growth modeling: frequency, usual quantity, heavy episodic drinking and volume.

Findings-All indices increased on average from ages 15 to 21 , peaked at approximately age 21, and gradually declined from ages 21 to 25 . Levels of use at age 21 were highly correlated across indices $(r=0.63-0.94, P<0.001$ ), but correlations among rates of change varied between pairs of indices. Heavy episodic drinking and volume had the strongest correlations over time $(r=0.64$ $0.81, P<0.001)$ and accounted for the greatest variance in alcohol use disorder symptoms $\left(R^{2}=\right.$ $0.35)$ and social and health consequences $\left(R^{2}=16\right)$ in emerging adulthood. Frequency and quantity had the weakest associations during adolescence $(r=0.49, P=0.001)$ and were uncorrelated during emerging adulthood $(r=0.23, P=0.09)$.

Correspondence to: Kara Thompson, Department of Psychology, University of Victoria, PO Box 1700 STN CSC, Victoria, BC, Canada V8W 2Y2. murrayk@uvic.ca.

\#Model fit for quantity was slightly below recommended levels for CFI. Fit of quantity is improved when the break-point is set at 20 , rather than $21\left(\chi^{2}(65)=137.59^{* * *}\right.$, RMSEA $\left.=0.04, \mathrm{CFI}=0.91\right)$. However, an examination of other indicators of model fit, such as the significance of the means and variance of the estimated growth parameters, the magnitude of the squared multiple correlations and the presence of large and significant modification indices, indicated that the fit of this model was adequate. Further, maintaining the breakpoint at 21 enabled comparison of the growth parameters with other alcohol indices.

Declaration of interests

None.

Supporting information

Additional Supporting Information may be found in the online version of this article at the publisher's web-site:

Appendix S1 Measures.

Appendix S2 Data structure.

Appendix S3 Estimated slopes from single-piece quadratic models.

Appendix S4 The factor-of-curves model. 
Conclusions-Among Canadian youth aged 15-25 years, measures of heavy episodic drinking and volume are the most strongly correlated over time and account for greater variance in alcoholrelated problems in emerging adulthood than either frequency or quantity alone.

\section{Keywords}

Adolescence; alcohol; development; latent growth modeling; measurement; young adult

\section{INTRODUCTION}

Internationally, alcohol use during adolescence and emerging adulthood is higher than at any other time across the life-span [1-4]. Accompanying these high drinking rates are marked peaks in the prevalence of alcohol abuse and dependence [5], alcohol-related injuries [6] and high-risk behaviors such as drinking and driving [7], aggression [8] and risky sexual behaviors [9]. Consequently, understanding how alcohol use and alcohol-related problems unfold during this period continues to be a major focus in research, prevention and policy efforts around the globe.

Alcohol use typically increases across adolescence, peaks in the early 20s, and decreases thereafter $[1,2,10,11]$. However, the operationalization of alcohol use varies considerably across studies, and not all studies support this typical pattern [12]. Studies typically use one or more of the following indices of alcohol involvement: frequency of use [13-15], typical quantity [16,17], average volume [18-20] and frequency of heavy episodic drinking (HED; consuming five or more drinks per occasion); HED is the most commonly used [10,21,22]. However, each dimension captures a different aspect of an individual's consumption pattern. Understanding the development of typical and atypical patterns of alcohol use requires longitudinal designs that can investigate the congruence of different measures of drinking. In the present study, we examined the longitudinal association among indices of alcohol involvement from age 15 to 25 years and examined their concurrent associations with alcohol-related problems in emerging adulthood.

Alcohol use is multi-dimensional [23-25], and each measure of use captures a distinct aspect of consumption. Frequency measures assess exposure to alcohol but neglect the importance of quantity consumed per occasion. Quantity measures evaluate the number of drinks consumed on a typical occasion, but are insensitive to variability in consumption, such as occasions of HED. Volume measures multiply frequency and quantity, but may obscure important patterns of alcohol use. For example, a low-frequency heavy drinker would be indistinguishable from a high-frequency moderate drinker. Finally, HED measures capture 'risky' consumption patterns, but do not account for drinking that occurs at lower levels.

Researchers have achieved some consensus that the briefest set of questions that should be asked to measure alcohol intake adequately are (i) usual quantity, (ii) overall frequency and (iii) frequency of HED [26]. Nevertheless, there is no standard solution for how to best aggregate indices or how to handle the multiple indices in multivariate analysis [27,28]. Thus, with little empirical evidence to support prioritizing one dimension over another, most alcohol indices are chosen for practical reasons (i.e. data availability) and analyses generally 
assume that common patterns will be observed across indices because they are highly correlated.

Although alcohol indices are highly correlated at a single time-point [24,29-31], longitudinal research suggests that indices may change differentially over time and are differentially related to health outcomes [12,32-40]. Following 714 emerging adults (ages 18-26), Casswell, Pledger \& Pratap [12] found that typical quantity peaked at age 21 and then declined, whereas drinking frequency continued to increase steadily over time.

Similarly, following 7344 adolescents from ages 12 to 23, Biehl et al. [14] found that both frequency and HED increased from ages 12 to 19, but that HED leveled off more than frequency after age 19. Further, acute consequences of alcohol, such as accidental injury, tend to be associated more strongly with HED than volume [32-36]. In contrast, chronic problems, such as alcohol use disorders, have been more closely linked with volume $[34,37,38]$. This is not to say that other indices are unrelated to problems. HED is also associated with abuse and dependence [39] and frequency is associated with alcohol-related problems, such as interpersonal conflict [40].

The complex association between alcohol indices is unclear, and most studies have been conducted with select measures at only one time-point [30]. An enhanced understanding of the longitudinal congruence of alcohol trajectories based on different indices is needed and could begin to reduce disparity in findings across studies caused by variation in choice of measurement.

This study examined similarities and differences in the trajectories of alcohol use across four indices of alcohol involvement (frequency, quantity, HED and volume) from ages 15 to 25. We also tested the possibility that the four indices are indicators of a higher-order alcohol use construct. Finally, concurrent associations between indices and alcohol-related problems in emerging adulthood were compared. Given that levels of alcohol use and rates of change tend to be higher among males compared to females $[12,41]$, gender was controlled in all analyses.

\section{METHOD}

\section{Participants}

The Victoria Healthy Youth Survey is a five-wave multi-cohort study of young people aged between 12 and 27 years. Participants were recruited from a medium-sized Canadian city using random digit dialing of 9500 private telephone listings. Of the 1036 eligible households with an adolescent aged 12-18 years, 662 adolescents agreed to participate [mean $=15.52 ;$ standard deviation $(\mathrm{SD})=1.93 ; 51 \%$ female; $85 \%$ Caucasian $]$, response rate 64\%. Participants were assessed biennially between 2003 and 2011. Response rates were $87 \%(n=578)$ at time $2,81 \%(n=539)$ at time $3,70 \%(n=459)$ at time 4 and $70 \%(n=$ $464)$ at time 5. Informed consent was obtained from parents/guardians and youth. Surveys were administered by trained interviewers. Youth received a $\$ 35$ honorarium. The living situation, parental education and ethnicity reported by participants were almost identical to the population from which the sample was drawn [42]. 
Alcohol use-For heavy episodic drinking, we asked: 'How often in the past 12 months have you had five or more drinks on one occasion?'; and for frequency: 'How often, in the past 12 months, have you had a drink of beer, wine, liquor or any other alcohol beverage?'. Response categories for HED and frequency were: never (0); a few times/year (1); a few times/month (2); once a week (3); and more than once a week (4). For quantity, we asked: 'In the past 12 months, how many drinks did you usually have on one occasion?'; respondents provided the number of drinks. Volume was calculated using the quantityfrequency (QF) method [43], which multiplies frequency by quantity, and divides by 52 , yielding the average number of drinks per week. The categorical frequency response was converted to number of drinking days by using the mid-point of the category (i.e. a few times/year $=6$; a few times $/$ month $=24$; once a week $=52$; and more than once a week $=$ 130). To reduce the skew, log transformation was applied to volume and quantity plus a small constant.

Alcohol-related problems-Alcohol-related problems in the last 12 months were available only at time 5. The Alcohol, Smoking and Substance Involvement and Screening Test (ASSIST) MINI plus [44] was used to assess symptoms of alcohol abuse and dependence as delineated in the Diagnostic and Statistical Manual of Mental Disorders, 4th edition (DSM-IV). However, given that the DSM-5 has moved towards a unitary construct of alcohol use disorder, varying only in terms of severity, 10 items from the ASSIST were summed to yield the number of symptoms ranging from 0 to 10 [45]. Examples of items included: (i) drinking interferes with other responsibilities; (ii) drinking more than planned; and (iii) tried to reduce or stop drinking but failed (for all items see Supporting information). One item, legal problems because of drinking, was dropped because it is no longer included as a symptom in the DSM-5 revision [45].

Social and health harms were assessed using the Harmful Effects of Alcohol Scale adapted from the Personalized Alcohol Use Feedback scale used by the Centre for Addictions and Mental Health (http://notes.camh.net/efeed.nsf/feedback). Participants were asked: 'In the last 12 months, has there ever been a time that you felt your alcohol use had a harmful effect on your ... (1) friendships and social life; (2) physical health; (3) outlook on life; (4) home life or marriage; (5) work, studies or employment; and (6) financial opportunities?'. The number of harms was summed yielding a total out of 6 .

Covariates included sex, mother's education [a proxy for socio-economic status (SES)], high school grades and ethnicity (see Supporting Information).

\section{Data preparation}

There were no significant differences in time 1 demographics and alcohol use between youth who remained in the study at time $5(n=460)$ and those who did not $(n=202)$. To model changes in alcohol use during two distinct developmental periods, adolescence and emerging adulthood, the five waves of data were restructured so that the time metric was age, rather than wave of assessment, using information from all age cohorts simultaneously. Data observations at ages 12,13,14, 26 and 27 were dropped (442 observations amounting to 25 
participants) due to low covariance coverage and low variance in alcohol use. Thus, analyses included a subsample of 637 participants (52\% female) aged 15-25 years (see Supporting Information for more details). All models were fitted using MPlus version 7 [46], using the full information maximum likelihood estimator [47].

\section{Analysis plan}

First, the trajectory of each index was established separately using piecewise growth curve models, each with a single intercept and two growth factors [48]. Slope 1 corresponded with ages 15-21 and slope 2 corresponded with ages $21-25$. The factor loadings for slope 1 were $-0.6-0.5-0.4-0.3-0.2-0.100000$ and 00000000.10 .20 .30 .4 for slope 2 . The intercept was centered at age 21 , the breakpoint of the piecewise growth model, and was informed by examining single piece quadratic models and their maxima (see online Supporting Information). ${ }^{\dagger}$ Research also suggests that alcohol use peaks at age 21 $[1,2,10,11]$. The piecewise approach was chosen instead of the single-piece quadratic model because it enabled us to make clear comparisons across alcohol indices in the different developmental time-periods. Further, interpreting covariances between linear slopes across alcohol indices was more straightforward than interpreting quadratic trends.

Next, associations among alcohol indices were tested using a multivariate piecewise growth model [49] in which the growth factors for all four indices were intercorrelated.

Additionally, a second-order extension of the multivariate model, a factor-of-curves model [49], tested whether the associations among indices could be described adequately by a high-order alcohol use construct (see online material for details). The factor-of-curves model is more parsimonious and preferred if the fit indices approach those of the multivariate model and meet the conventional standards of model fit [49,50]; comparative fix index (CFI) $\geq 0.95$ and root mean square error of approximation (RMSEA) $\leq 0.06$ [although CFI and the Tucker-Lewis Index (TLI) $\geq 0.90$ and RMSEA $\leq 0.10$ are often considered an adequate fit].

\section{RESULTS}

\section{Characteristics of the sample}

For all indices, the mean increased until age 20 and then stabilized or declined (Table 1).

The average cross-sectional correlations were: HED and quantity, $r=0.70\left(r_{\text {range }}=0.56-\right.$ $0.80)$; HED and frequency, $r=0.71\left(r_{\text {range }}=0.62-0.70\right)$; HED and volume, $r=0.77\left(r_{\text {range }}=\right.$ $0.73-0.81)$; frequency and volume, $r=0.70\left(r_{\text {range }}=0.64-0.70\right)$; volume and quantity, $r=$ $0.72\left(r_{\text {range }}=0.62-0.80\right)$; and frequency and quantity, $r=0.39\left(r_{\text {range }}=0.25-0.67\right)$.

The mean number of alcohol use disorder (AUD) symptoms reported by participants was $1.71(\mathrm{SD}=1.89)$. Thirty-three per cent reported two to three symptoms indicative of a moderate AUD, and 12\% reported four or more symptoms indicative of a severe AUD [45]. The mean number of social and health harms reported by participants at time 5 was 0.71 (SD =1.30). Thirty per cent reported one or more harms.

$\dagger$ Examination of the fitted values from the single piece quadratic model showed the maxima to be at age 21 for heavy episodic drinking (HED) and volume. Frequency appeared to peak slightly later at age 22 and quantity appeared to peak slightly earlier at age 20. However, in order to facilitate comparisons of growth parameters across alcohol indices, age 21 was used for all four measures. 


\section{Trajectories of alcohol use}

The piecewise growth models fitted the data adequately. ${ }^{\dagger}$ For all indices, alcohol use increased on average from ages 15 to 21 and declined from ages 21 to 25 (Table 2). There was significant between-person variability around the intercepts and slopes of each index, indicating differences in the individual trajectories of drinking experienced by participants. Males reported significantly higher levels of drinking at age 21 on all indices, and faster increases in HED and volume from ages 15 to 21 than females. The fitted values from each piecewise model are plotted in Fig. 1.

\section{Associations among alcohol indices over time}

Correlations among levels and among slopes-The multivariate model fitted the data well, $\chi^{2}{ }_{(1819.80, \mathrm{n}=637)}=886.00, P=0.000, \mathrm{RMSEA}=0.04, \mathrm{CFI}=0.92, \mathrm{TLI}=0.91$. Correlations among levels of alcohol use at age 21 (intercept) across all four indices were positive and strong in magnitude ( $\left.r_{\text {range }}=0.63-0.94\right)$ (Table 3 ). Correlations among rates of change in alcohol use from ages 15 to 21 (slope 1) were also positive and moderate to strong in magnitude $\left(r_{\text {range }}=0.49-0.82\right)$. Finally, correlations among rates of change in alcohol from ages 21 to 25 (slope 2 ) were positive and small to strong in magnitude $\left(r_{\text {range }}=0.23-\right.$ 0.83 ). The strongest correlations were between volume and HED, which shared $88 \%$ of their variance in levels of drinking at age $21,66 \%$ of the variance in change from ages 15 to 21 and $41 \%$ of the variance in change from ages 21 to 25 .

\section{Correlations between levels and slopes}

Rates of change from ages 15 to 21 were positively correlated with drinking levels at age 21 $\left(I_{\text {range }}=0.16-0.72\right)$ for each index and across indices, indicating that individuals who increased their drinking faster from ages 15-21 had higher levels of alcohol use at age 21 compared to individuals whose drinking increased more slowly. Correlations between levels of drinking at age 21 and rates from change from ages 21 to 25 were negative for each index and across indices ( $r_{\text {range }}=-0.22$ to -0.47 ), showing that individuals with higher levels of alcohol use at age 21 did not decline in their drinking as fast as those with lower levels. Finally, faster rates of increase from ages 15 to 21 were associated with slower declines in drinking from ages 21 to 25 for each index ( $r_{\text {range }}=-0.37$ to -0.46 ). Further, faster rates of increase in volume or HED from ages 15 to 21 was associated with slower rates of decrease in all other indices from ages 21 to 25 ( $r_{\text {range }}=-0.25$ to -0.46$)$.

\section{A higher-order alcohol index}

The loadings of the first-order intercepts and slopes on the higher-order factors were significant $[\mathrm{HED}=1.18(0.02), P<0.001$; quantity $=0.57(0.02), P<0.001$; frequency $=$ $1.16(0.02), P<0.001]$, and the higher-order factors accounted for a substantial proportion of the variation in initial levels and rates of change. However, fit indices were outside the ranges associated with acceptable model fit, $\chi^{2}(538, \mathrm{n}=637)=1502.38, P<0.001$, RMSEA $=$ $0.06, \mathrm{CFI}=0.80, \mathrm{TLI}=0.81$ (Table 4 ). The model did not account sufficiently for the correlations among the intercepts of volume and frequency (modification index $=141.69$ ), slope 2 of volume and frequency (modification index $=121.26$ ) and slope 2 of quantity and frequency (modification index $=83.72$ ). The poor fit indicates that pairs of indices correlate 
more or less strongly over time than would be implied by a model positing a single latent alcohol use factor.

\section{Predicting alcohol-related problems in emerging adulthood}

As expected, all indices were significantly related to alcohol-related problems at Time 5. HED and volume accounted for the greatest proportion of variance in AUD symptoms (34\% and $32 \%$, respectively) and social and health harms (16\% and $15 \%$, respectively). In contrast, quantity and frequency accounted for only $23 \%$ and $19 \%$ of the variance in AUDs and only $9 \%$ of the variance in social and health harms (Table 5).

\section{DISCUSSION}

This study examined the longitudinal associations among four alcohol indices during adolescence and emerging adulthood. Consistent with average developmental trends reported in past research $[1,2,10,12]$, all indices increased on average from ages 15 to 21 , peaked at approximately age 21 and gradually declined from ages 21 to 25 . Moreover, for each index, faster rates of increase in drinking during adolescence were associated with slower rates of decline in emerging adulthood. Although all indices increased then decreased, there was variation in the rate of these changes. For example, while we could not test this explicitly, quantity appeared to increase the slowest during adolescence, whereas frequency appeared to increase the fastest during adolescence. Moreover, of the four indices, HED and volume appeared the most similar in their average trends over time. The multivariate findings support these differences and similarities. For example, during adolescence HED and volume shared approximately $65 \%$ of their variance in change over time, whereas HED shared only $27 \%$ of its variance with quantity and only $32 \%$ of its variance with frequency.

Overall, the multivariate findings showed that levels were more strongly correlated across indices than rates of change, replicating previous studies finding strong concurrent correlations across indices [24,29-31]. Extending previous research, correlations among rates of change suggest that individuals who increased or decreased in one index also tended to increase or decrease in other indices. The single exception was the very small nonsignificant correlation between rate of change in quantity and frequency from ages 21 to 25 .

However, the magnitude of associations varied between pairs of indices. Volume was highly correlated with quantity and frequency, because volume was a function of frequency and quantity. Of more interest were the very strong correlations between HED and volume over time. This is consistent with some previous research [19]. Additionally, faster rates of increase in HED and volume during adolescence were associated with slower rates of decline in all indices of alcohol involvement during emerging adulthood, suggesting that early high levels of HED and volume may be indicative of future alcohol use in general. Supporting these strong associations, HED and volume accounted for similar amounts of variance in alcohol-related problems during emerging adulthood and accounted for more variance than either quantity or frequency alone. The weakest associations over time were consistently between quantity and frequency. Findings also showed that these indices 
explained the least amount of variance in alcohol-related problems. Epidemiological studies have long recognized the limitations of using measures of drinking frequency alone [51].

Given the variation in pairwise associations among indices across adolescence and young adulthood, the data did not support the idea that the four indices could be explained by a common set of growth factors. This suggests that indices differ in their trajectories over time and may be differentially related to outcomes. The variability in associations among indices may reflect developmental shifts in the predominate pattern of consumption from one of low-frequency high-quantity during adolescence to higher-frequency lower-quantity in young adulthood [52]. As a result of this shift, the indices used to assess alcohol involvement, and the associations between them, may perform differently and become more or less meaningful over time. For example, while high frequency of drinking during adolescence may be indicative of severity of alcohol consumption, the meaning of drinking frequency changes as high-frequency levels become relatively normative during emerging adulthood [53,54].

The strength of the association between HED and volume probably reflects the predominant pattern of alcohol consumption during this developmental period of low-frequency highquantity [52]. As a result, HED and volume capture similar patterns of alcohol consumption, and their stronger correlations over time may indicate that either measure would be adequate to capture meaningful patterns of risky consumption associated with these types of alcoholrelated problems. However, there is still a substantial amount of variance in alcohol-related problems left to be explained, highlighting the importance of other influences on the experience of problems. Moreover, it is likely that associations between HED and volume may decrease over time as drinking patterns shift to high-frequency low-quantity in adulthood.

\section{Limitations}

The ethnicity and economic diversity of participants were consistent with the population sampled [42] and the prevalence of alcohol use and related problems were similar to other Canadian studies [54]. Despite this, these findings may not be generalizable to other cultures or more high-risk populations, which may hold different attitudes towards drinking and have different patterns of consumption. Further, measures of indices can vary considerably across studies. For example, the reference period may be past year, past month, past week or most recent drinking occasion. As such, the findings may not generalize to measures using different reference periods. Research also shows that graduated frequency (GF), an alternative measure of volume, yields higher estimates of overall alcohol consumption compared to the QF approach, particularly for young adults aged 18-24 [55]. Future research should examine the association among indices including the GF approach. Finally, the comparison of alcohol indices in this paper was not a rigorous test of reliability or validity, which have been extensively investigated and reviewed elsewhere $[37,51,56]$.

\section{CONCLUSIONS}

The non-equivalence of alcohol measures across studies can create difficulties in interpretation and generalization of knowledge. The present findings showed that HED and 
volume had the greatest concordance in developmental trends and accounted for the greatest variance in alcohol-related problems during emerging adulthood. Much research on trajectories of alcohol use has relied on measures of HED and the current findings support the continued use of this measure and measures of volume, as both of these performed better in predicting alcohol-related problems than the other alcohol consumption measures examined here. The current findings can help to guide researchers selecting measures of alcohol involvement for inclusion in studies. However, researchers should still be cautious in generalizing longitudinal patterns and predictive relationships across different indices of alcohol involvement.

\section{Acknowledgments}

We are grateful to all adolescents (now adults!) who participated in this research and to everyone who worked on this project and made it possible, including Dr Vincenza Gruppuso (University of Victoria, Dr Doug Baer (University of Victoria) and Dr Helene White (Rutgers University). The Victoria Healthy Youth Survey study has been supported financially by grants from the Canadian Institute for Health Research [including \#838-20000-075 (B.L.), \#79917 (T.S.) and \#93533 (B.L.)] and this research study was additionally supported by a Canadian Institute for Health Research Doctoral Award to K.T. (\#104612).

\section{References}

1. Johnston, LD., O’Malley, PM., Bachman, JG., Schulenberg, JE. Monitoring the Future national survey results on drug use, 1975-2011. Volume II. College students and adults ages 19-50. Ann Arbor: Institute for Social Research, The University of Michigan; 2012. p. 314

2. Johnston, LD., O’Malley, PM., Bachman, JG., Schulenberg, JE. Monitoring the Future national survey results on drug use, 1975-2011. Volume I: Secondary school students. Ann Arbor: Institute for Social Research, The University of Michigan; 2012. p. 760

3. Health Canada. The Canadian Alcohol and Drug Use Monitoring Survey: highlights report. Ottawa: Health Canada; 2010. Available at: http://www.hc-sc.gc.ca/hc-ps/drugs-drogues/cadums-esccadeng.phpArchived at http://www.webcitation.org/6NXEUZxyw on 20 February 2014 [accessed 10 January 2013]

4. Saggers, S., Chikritzhs, TN., Allsop, S. Young People and Alcohol: Reducing the Risk. Australian Research Alliance for Children and Youth; Canberra, Australia: 2009.

5. Littlefield, A., Sher, KJ. Alcohol use disorders in young adulthood. In: Grant, JE., Potenza, MN., editors. Young Adult Mental Health. New York: Oxford University Press; 2010. p. 292-310.

6. Taylor B, Rehm J, Room R, Patra J, Bondy S. Determination of lifetime injury mortality risk in Canada in 2002 by drinking amount per occasion and number of occasions. Am J Epidemiol. 2008; 168:1119-25. [PubMed: 18718895]

7. Beck KH, Kasperski SJ, Caldeira KM, Vincent KB, O'Grady KE, Arria AM. Trends in alcoholrelated traffic risk behaviors among college students. Alcohol Clin Exp Res. 2010; 34:1472-8. [PubMed: 20528819]

8. Neal DJ, Fromme K. Event-level covariation of alcohol intoxication and behavioral risks during the first year of college. J Consult Clin Psychol. 2007; 75:294-306. [PubMed: 17469887]

9. Mäkelä P, Mustonen H. Relationships of drinking behavior, gender, and age with reported negative and positive experiences related to drinking. Addiction. 2000; 95:727-36. [PubMed: 10885047]

10. Muthén BO, Muthén LK. The development of heavy drinking and alcohol-related problems from ages 18-37 in a U.S. national sample. J Stud Alcohol. 2000; 61:290-300. [PubMed: 10757140]

11. Maggs, J., Schulenberg, J. Initiation and course of alcohol consumption among adolescents and young adults. In: Galanter, M., editor. Recent Developments in Alcoholism. Vol. 17. New York: Plenum Press; 2005. p. 29-47.

12. Casswell S, Pledger M, Pratap S. Trajectories of drinking from 18 to 26 years: identification and prediction. Addiction. 2002; 97:1427-37. [PubMed: 12410783] 
13. Brown E, Catalano R, Fleming C, Haggerty K, Abbott R. Adolescence substance use outcomes in the raising health children project: a two-part latent growth curve analysis. J Consult Clin Psychol. 2005; 73:699-710. [PubMed: 16173857]

14. Biehl M, Natsauki M, Ge X. The influence of pubertal timing on the alcohol use and heavy drinking trajectories. J Youth Adolesc. 2007; 36:153-67.

15. Li F, Barrera M, Hops H, Fisher KJ. The longitudinal influence of peers on the development of alcohol use in late adolescence: a growth mixture analysis. J Behav Med. 2002; 25:293-315. [PubMed: 12055779]

16. Flory K, Lynam D, Milich R, Leukefeld C, Clayton R. Early adolescent through young adult alcohol and marijuana use trajectories: early predictors, young adult outcomes, and predictive utility. Dev Psychopathol. 2004; 16:193-213. [PubMed: 15115071]

17. Wiesner M, Weichold K, Silbereisen RK. Trajectories of alcohol use among adolescent boys and girls: identification, validation, and sociodemographic characteristics. Psychol Addict Behav. 2007; 21:62-75. [PubMed: 17385956]

18. Maggs J, Schulenberg J. Reasons to drink and not to drink: altering trajectories of drinking through an alcohol misuse prevention program. Appl Dev Sci. 1998; 2:48-60.

19. Jackson KM, Sher K. Similarities and differences of longitudinal phenotypes across alternate indices of alcohol involvement: a methodological comparison of trajectory approaches. Psychol Addict Behav. 2005; 19:339-51. [PubMed: 16366806]

20. Chassin L, Flora D, King K. Trajectories of alcohol and drug use and dependence from adolescence to adulthood: the effects of familial alcoholism and personality. J Abnorm Psychol. 2004; 4:482-98.

21. Schulenberg J, O’Malley PM, Bachman JG, Wadsworth KN, Johnston LD. Getting drunk and growing up: trajectories of frequent binge drinking during the transition to young adulthood. $\mathrm{J}$ Stud Alcohol. 1996; 57:289-304. [PubMed: 8709588]

22. Costanzo P, Malone P, Belsky D, Kertesz S, Pletcher M, Sloan F. Longitudinal differences in alcohol use in early adulthood. J Stud Alcohol Drugs. 2007; 68:727-37. [PubMed: 17690807]

23. Auerbach KJ, Collins LM. A multidimensional developmental model of alcohol use during emerging adulthood. J Stud Alcohol. 2006; 67:917-25. [PubMed: 17061010]

24. Mason WA, Kosterman R, Haggerty K, Hawkins JD, Redmond C, Spoth R, et al. Dimensions of adolescents alcohol involvement at predictors of young-adult major depression. J Stud Alcohol Drugs. 2008; 69:275-85. [PubMed: 18299769]

25. Newcomb, MD. Understanding the multidimensional nature of drug use and abuse: the role of consumption, risk factors, and protective factors. In: Glantz, MD., Pickens, R., editors. Vulnerability to Drug Abuse. Washington DC: American Psychological Association; 1992. p. 255-97.

26. Dawson D, Room R. Towards agreement on ways to measure and report drinking patterns and alcohol-related problems in adult general population surveys: Skarpo Conference overview. J Subst Abuse. 2000; 12:1-21. [PubMed: 11288465]

27. Room R. Measuring drinking patterns: the experience of the last half century. J Subst Abuse. 2000; 12:23-31. [PubMed: 11288472]

28. Rehm J, Gmel G. Aggregating dimensions of alcohol consumption to predict medical and social consequences. J Subst Abuse. 2000; 12:155-68. [PubMed: 11288468]

29. Weitzman ER, Nelson TF. College student binge drinking and the 'prevention paradox': implications for prevention and harm reduction. J Drug Educ. 2004; 34:247-66. [PubMed: 15648886]

30. Borsari B, Neal D, Collins S, Carey K. Differential utility of three indexes of risky drinking for predicting alcohol problems in college students. Psychol Addict Behav. 2001; 15:321-4. [PubMed: 11767264]

31. Wyllie A, Zhang J, Casswell S. Comparison of six alcohol consumption measures from survey data. Addiction. 1994; 89:425-30. [PubMed: 8025496]

32. Stockwell T, Buxton J, Duff C, Marsh D, MacDonald S, Muchelow W, et al. The British Columbia alcohol and other drug monitoring system: overview and early progress. Contemp Drug Probl. 2009; 36:458-84. 
33. Rehm J, Gmel G. Patterns of alcohol consumption and social consequences. Results from an 8-year follow-up study in Switzerland. Addiction. 1999; 94:899-912. [PubMed: 10665078]

34. Rehm J, Room R, Graham K, Monterio M, Gmel G, Sempos CT. The relationship of average volume of alcohol consumption and patterns of drinking to burden of disease: an overview. Addiction. 2003; 98:1209-28. [PubMed: 12930209]

35. Bondy S. Overview of studies on drinking patterns and consequences. Addiction. 1996; 91:166374. [PubMed: 8972924]

36. Single E, Brewster J, MacNeil P, Hatcher J, Trainor C. The 1993 General Social Survey II: alcohol problems in Canada. Can J Public Health. 1996; 86:402-7.

37. Gmel G, Rehm J. Measuring alcohol consumption. Contemp Drug Probl. 2004; 31:467-540.

38. Rehm J, Ashley MJ, Room R, Single E, Bondy S, Ferrence R, et al. On the emerging paradigm of drinking patterns and their social and health consequences. Addiction. 1996; 91:1615-22. [PubMed: 8972920]

39. Dawson D, Li T, Grant B. A prospective study of risky drinking: at risk for what? Drug Alcohol Depend. 2008; 95:62-72. [PubMed: 18243584]

40. Duncan S, Alpert A, Duncan T, Hops H. Adolescent alcohol use development and young adult outcomes. Drug Alcohol Depend. 1997; 49:39-48. [PubMed: 9476698]

41. Windle M, Mun EY, Windle RC. Adolescent-to-young adulthood heavy drinking trajectories and their prospective predictors. J Stud Alcohol. 2005; 66:313-22. [PubMed: 16047520]

42. Statistics Canada. [accessed 14 March 2013] Census of population. 2001. Available at: http:// www12.statcan.gc.ca/english/census01/Products/standard/themes/DataProducts.cfm?S=1Archived at http://www.webcitation.org/6NX9s3mkq on 20 February 2014

43. Stockwell T, Zhao J, Thomas G. Should alcohol policies aim to reduce total alcohol consumption? New analyses of Canadian drinking patterns. Addict Res Theory. 2009; 17:135-51.

44. Lecrubier Y, Sheehan D, Weiller E, Amorim P, Bonora I, Sheehan K, et al. The MINI International Neuropsychiatric Interview (M.I.N.I.). A short diagnostic structured interview: reliability and validity according to the CIDI. Eur Psychiatry. 1997; 12:224-31.

45. Dawson DA, Goldstein R, Grant B. Differences in the profiles of DSM-IV and DSM-5 alcohol use disorders: implications for clinicians. Alcohol Clin Exp Res. 2013; 37:E305-13. [PubMed: 22974144]

46. Muthén, LK., Muthén, BO. Mplus User's Guide. 6. Los Angeles, CA: Muthén \& Muthén; 19982010.

47. Arbuckle, JL. Full information estimation in the presence of incomplete data. In: Marcoulides, GA., Schumacker, RE., editors. Advanced Structural Equation Modeling: Issues and Techniques. New Jersey: Lawrence Erlbaum Associates; 1996. p. 243-77.

48. Li F, Duncan T, Duncan S, Hops H. Piecewise growth mixture modeling of adolescent alcohol use data. Struct Equ Modeling. 2001; 8:175-204.

49. Duncan, TE., Duncan, SC., Strycker, LA. An Introduction to Latent Variable Growth Curve Modeling: Concepts, Issues, and Applications. 2. New York: Psychology Press; 2006.

50. Hu L, Bentler P. Cutoff criteria for fit indexes in covariance structure analysis: conventional criteria versus new alternatives. Struct Equ Modeling. 1999; 6:1-55.

51. Rehm J. Measuring quantity, frequency and volume of drinking. Alcohol Clin Exp Res. 1998; 22:4S-14S. [PubMed: 9603301]

52. Deas D, Riggs P, Langenbucher J, Goldman M, Brown S. Adolescents are not adults: developmental considerations in alcohol users. Alcohol Clin Exp Res. 2000; 24:232-7. [PubMed: 10698377]

53. Kahler C, Hoeppner B, Jackson K. A Rasch model analysis of alcohol consumption and problems across adolescence and young adulthood. Alcohol Clin Exp Res. 2009; 33:663-73. [PubMed: 19183135]

54. Health Canada. Canadian Addiction Survey (CAS): a national survey of Canadians' use of alcohol and other drugs: prevalence of use and related harms: detailed report. Ottawa, Ontario: Canadian Centre on Substance Abuse; 2005. 
55. Stockwell T, Donath S, Cooper-Stanbury M, Chikritzhs T, Catalano P, Mateo C. Under-reporting of alcohol consumption in household surveys: a comparison of quantity-frequency, graduatedfrequency and recent recall. Addiction. 2004; 99:1024-33. [PubMed: 15265099]

56. Room, R. Measuring alcohol consumption in the United States: methods and rationales. In: Kozlowski, LT.Annis, HM.Cappell, HD.Glaser, FB.Goodstadt, MS.Israel, Y., et al., editors. Research Advances in Alcohol and Drug Problems. Vol. 10. New York: Plenum Press; 1990. p. 40-80. 

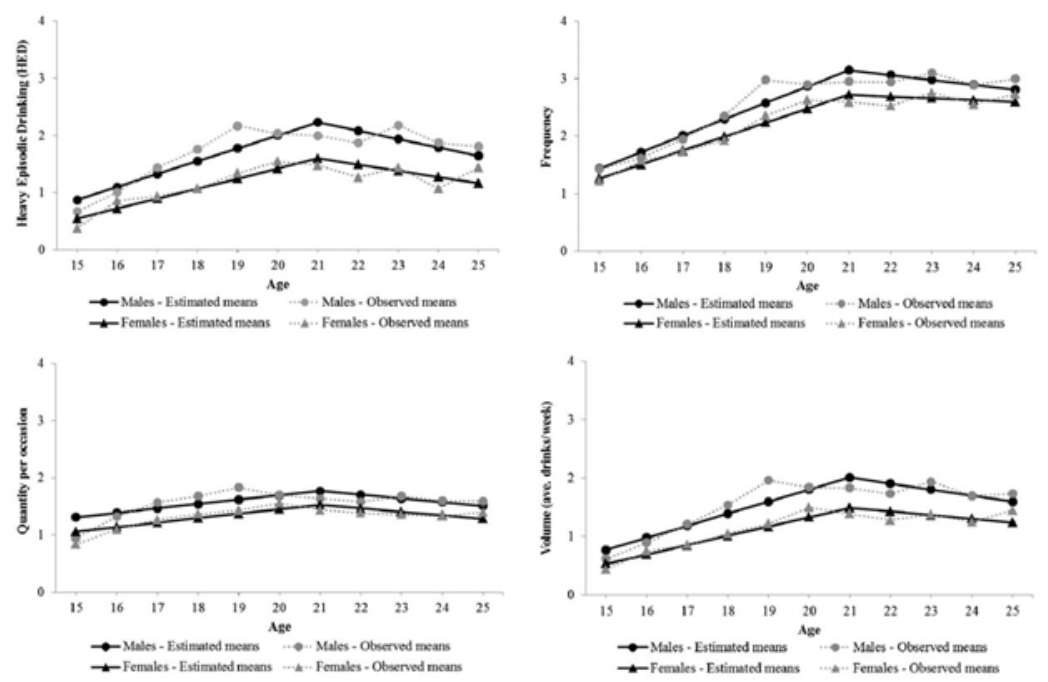

Figure 1.

Estimated slopes from the univariate piecewise latent growth models for heavy episodic drinking (top left), frequency (top right), quantity (bottom left) and volume (bottom right). Quantity and volume are scaled as the $\log +1$ 


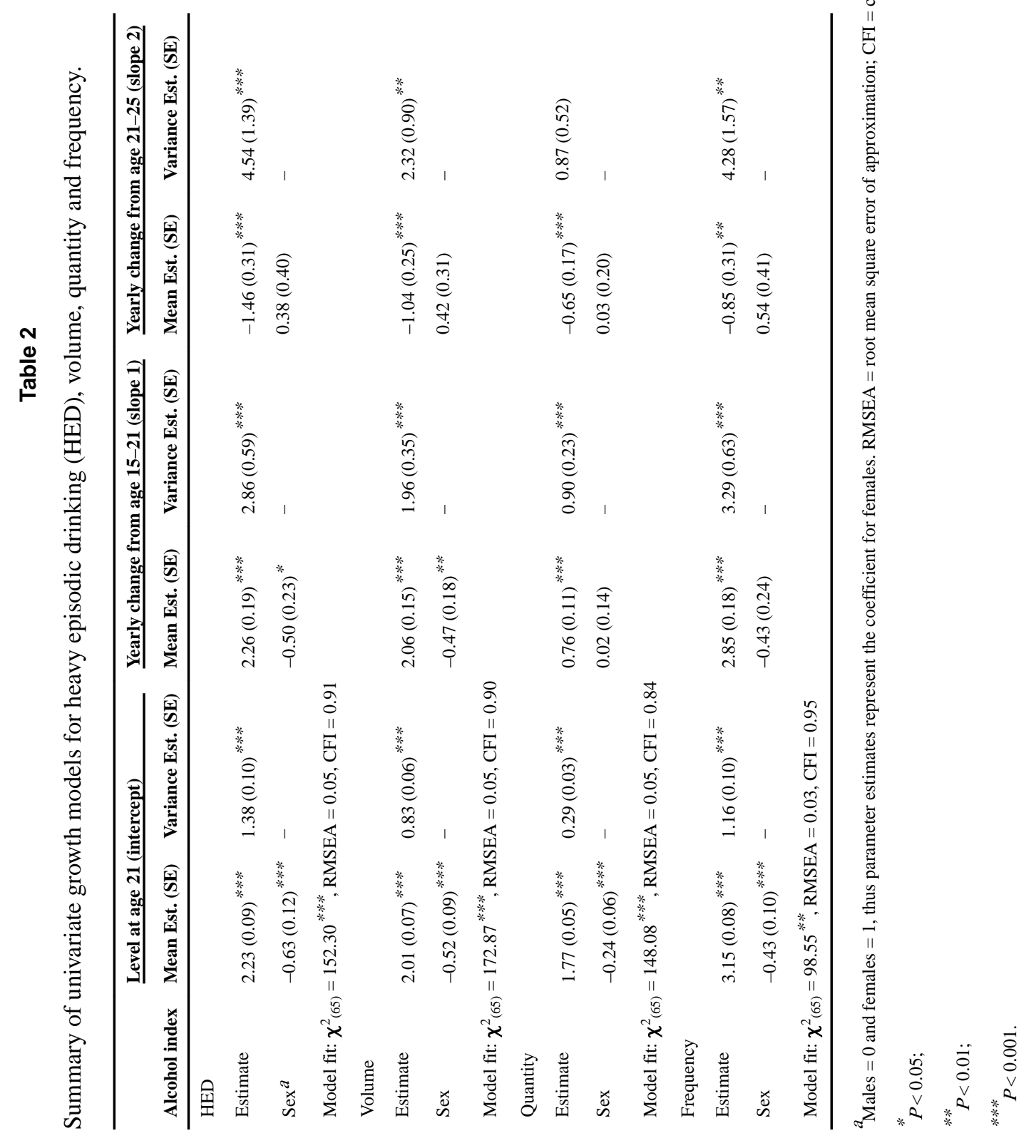




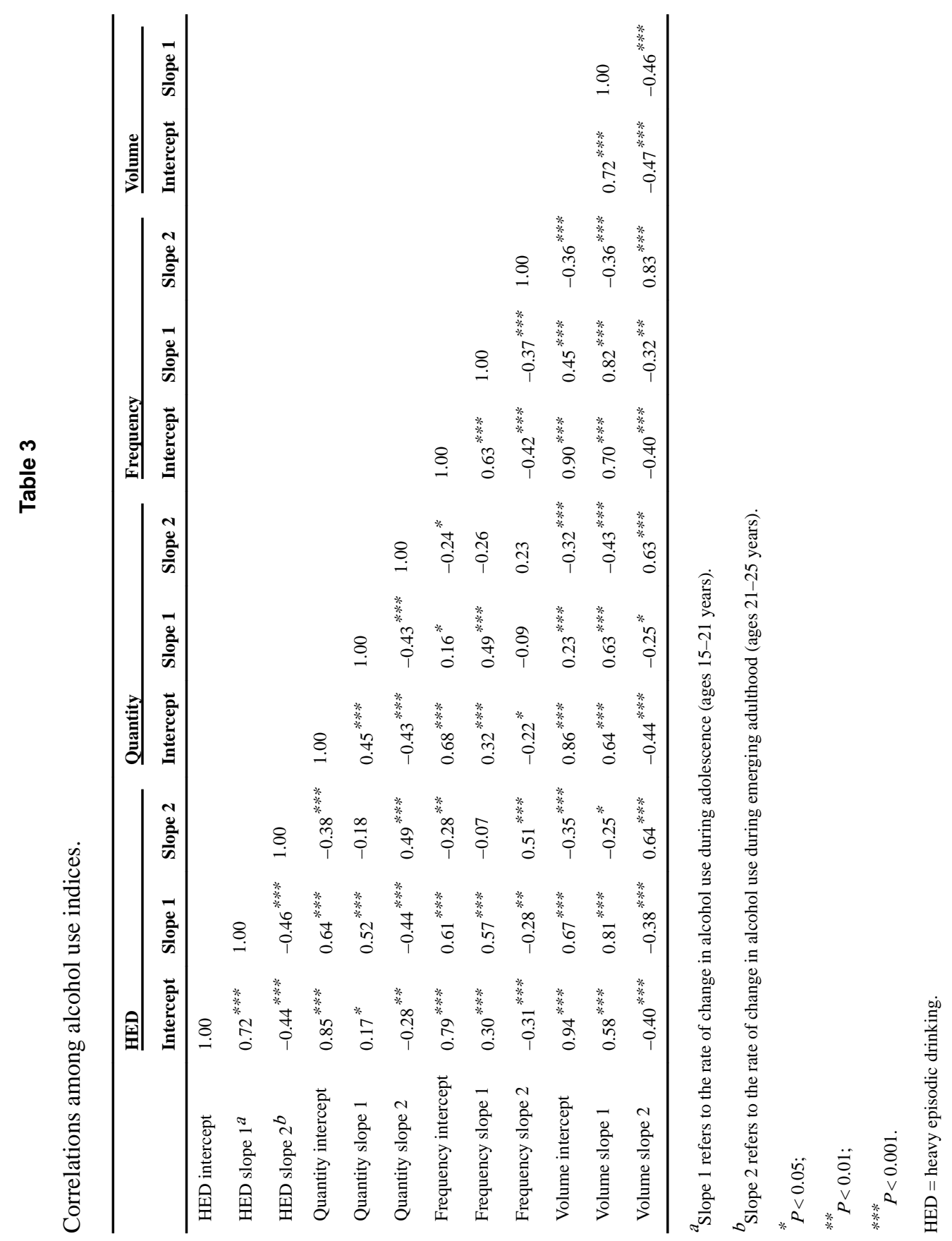




\section{Table 4}

Parameter estimates from the factor-of-curves LGM.

\begin{tabular}{ll}
\hline & Coeff. (SE) \\
\hline Means & $1.78(0.05)^{* * *}$ \\
Intercept & $1.89(0.10)^{* * *}$ \\
Slope 1 & $-1.08(0.16)^{* * *}$ \\
Slope 2 & \\
Variances & $1.11(0.08)^{* * *}$ \\
Intercept & $4.12(0.32)^{* * *}$ \\
Slope 1 & $7.46(0.87)^{* * *}$ \\
Slope 2 & \\
Covariance & $1.49(0.13)^{* * *}$ \\
Intercept with slope 1 & $-1.68(0.21)^{* * *}$ \\
Intercept with slope 2 & $-3.07(0.42)^{* * *}$ \\
Slope 1 with slope 2 & \\
\hline$* * *$ \\
$P<0.001$.
\end{tabular}




\section{Table 5}

Unstandardized estimates and standard errors (SE) for alcohol-related social and health consequences and symptoms of alcohol use disorders in emerging adulthood.

\begin{tabular}{llllll}
\hline & \multicolumn{2}{l}{ Social and health consequences } & & \multicolumn{2}{l}{ Alcohol use disorder symptoms } \\
\cline { 2 - 3 } Alcohol index & Unadjusted coeff. (SE) & Adjusted coeff. (SE) & & Unadjusted coeff. (SE) & Adjusted coeff. (SE) \\
\hline HED & $0.43(0.05)$ & $0.46(0.05)$ & $0.91(0.06)$ & $0.93(0.06)$ \\
$R^{2}$ & $0.16(1.20)$ & $0.16(1.19)$ & $0.34(1.51)$ & $0.35(1.51)$ \\
Volume & $0.52(0.06)$ & $0.55(0.06)$ & $1.09(0.08)$ & $1.12(0.08)$ \\
$R^{2}$ & $0.15(1.21)$ & $0.15(1.20)$ & $0.31(1.57)$ & $0.32(1.55)$ \\
Quantity & $0.68(0.10)$ & $0.70(0.11)$ & $1.52(0.13)$ & $1.53(0.14)$ \\
$R^{2}$ & $0.10(1.24)$ & $0.09(1.24)$ & $0.23(1.64)$ & $0.24(1.63)$ \\
Frequency & $0.31(0.05)$ & $0.31(0.05)$ & $0.63(0.07)$ & $0.63(0.07)$ \\
$R^{2}$ & $0.09(1.25)$ & $0.09(1.24)$ & $0.18(1.70)$ & $0.18(1.69)$ \\
\hline
\end{tabular}

Adjusted models controlled for age at baseline, sex, ethnicity, socio-economic status (SES) and high school grades. All coefficients were significant at $P<0.001 . \mathrm{HED}=$ heavy episodic drinking. 